\title{
ANTIULCER ACTIVITY OF CONTROLLED RELEASE FORMULATION CONTAINING AQUEOUS EXTRACT OF ACACIA CATECHU WILLD ON RODENT MODELS
}

\author{
BASANT KHARE, NAINA DUBEY, AKASH SHARMA \\ Sagar Institute of Pharmaceutical Sciences, Sagar (M.P.) \\ Email: akashsharma19486@gmail.com
}

Received: 12 Jun 2018, Revised and Accepted: 07 Aug 2018

\begin{abstract}
Objective: To study the Antiulcer activity of aqueous extract of acacia catechu willd on rodent models by controlled release formulation.

Methods: Microspheres were prepared by a solvent evaporation method and were evaluated for various parameters like SEM, stability and in vitro relese. And acacia catechu willd loaded microspheres were evaluated for in vivo study involving Gastric ulceration in rats was induced by Ethanol/HCl. Ulcer genic effect (Ulcer Index), pH and Total acidity, Histopathological studies.
\end{abstract}

Results: Results indicated that Acacia catechu willd microspheres contain some active constituents like flavanoid which are responsible for its antiulcer activity. Also it was observed aqueous extract loaded microspheres showed maximum activity was found (200 mg/kg) with standard Cimetidine $(100 \mathrm{mg} / \mathrm{kg})$ also, the results revealed that aqueous extract microspheres at $200 \mathrm{mg} / \mathrm{kg}$ had reduced ulcer incidence significantly, when compared to the control as evident by decrease in ulcer score in the model.

Conclusion: Based on the result it can be concluded that microspheres loaded with aqueous extracts of Acacia catechu willd produced promising antiulcer activity and were safe.

Keywords: Cimetidine, Acacia catechu willd, Herbal drug, Microspheres, Control group

(C) 2018 The Authors. Published by Innovare Academic Sciences Pvt Ltd. This is an open access article under the CC BY license (http://creativecommons.org/licenses/by/4.0/] DOI: http://dx.doi.org/10.22159/ijcpr.2018v10i5.29689

\section{INTRODUCTION}

'Traditional' use of herbal medicines implies substantial historical use, and this is certainly true for many products that are available as 'traditional herbal medicines.' In many developing countries, a large proportion of the population relies on traditional practitioners in order to meet health care needs. Although modern medicine may exist side-by-side with such traditional practice, herbal medicines have often maintained their popularity for historical and cultural reasons.

The WHO monographs, for example, describe the herb itself by a number of criteria (including synonyms and vernacular names) and fee bob part commonly used, its geographical distribution, tests used to identify and characterize the herb (including macroscopic and microscopic examination and purity testing), the active principles (when known), dosage forms and dosing, medicinal uses, pharmacology, contra-indications and adverse reactions [1-3].

\section{Indian medicinal plant used in the treatment of ulcer}

In spite one of being well known medicinal plant used traditional Indian medicine to treat several ailments, associate studies to the pharmacological properties of some medicinal plant are very extinct. On being an investigation, this plant shows that these medicinal plants could prevent ulcer in rats in a dose-dependent manner as well as studying the antiulcer activity of an acute toxicity of some medicinal plants. The presence of important secondary metabolites like flavonoids tannins, glycosides, terpenoids, etc [4-7].

\section{Controlled release formulation}

Controlled release dosage form covers a wide range of prolonged action formulation which provide continuous release of their active ingredients at a predetermined rate, and for a predetermined time the majority of these formulation are designed for oral administration, however recently such device has also been introduced for parenteral administration ocular insertion and for transdermal application.

The most important objective for the development of these systems is to furnish and extended duration of action and thus assure greater patient compliance.
Mucoadhesive microspheres have been accepted as a process to achieve controlled drug delivery by prolonging the residence time of the dosage form at the site of absorption thereby improving and enhancing the bioavailability of drugs. Mucoadhesive drug delivery systems is one of the most important novel drug delivery systems with its various advantages, and it has a lot of potential in formulating dosage forms for various chronic diseases.

Hence prepared mucoadhesive microspheres may be an effective strategy for the development of an easy, reproducible and cost-effective method for safe and effective oral drug therapy. In recent years such Mucoadhesive microspheres have been developed for oral, buccal, nasal, ocular, rectal and vaginal for either systemic or local effects [8-12].

\section{Plant profile}

Acacia catechu willd-This name is the accepted name of a species in the genus Acacia (family Leguminosae).

\section{Chemical constituents}

Main chemical constituents of Acacia catechu Willd are catechin, $(-)$ epicatechin, epigallocatechin, epicatechin gallate, epigallocatechin gallete rocatechin, phloroglucin, protocatechuic acid, quercetin, poriferasterol glucosides, poriferasterol acyglucosides, lupenone, lupeol, procyanidin, kaempferol, dihydrokaempferol, taxifolin, (+)afzelchin gum and mineral The chief phyto constituent of the heartwood are catechin and epicatechin. Catechins have significant antioxidant and antimicrobial effects.

\section{Medicinal application}

It is used for treating high blood pressure, leucorrhoea, diarrhea, dysentery, leprosy, colitis, gastritis, bronchitis and cough, and also gargled for gingivitis, toothache, sore throat and mouth infections.

Externally, Acacia catechu bark powder is applied for boils, ulcers and cutaneous eruptions. A small piece, held in the mouth and Allowed to dissolve slowly, is an excellent remedy in the relaxation of the uvula and simple pharyngitis $[13,14]$.

Acacia catechu willd is highly valuable for its powerful astringent and antioxidant activities. It is commonly known as Katha which is 
an indispensable ingredient of Pan that is beetle leaf preparation chewed in India.

It is tonic and aphrodisiac, cures leucorrhoea, piles, erysipelas, useful in diarrhea, spongy gums, and relaxation of uvula and hypertrophy of the tonsil. Katha or decoction of heartwood is applied in the mouth and on the tongue to cure mouth Ulcer. It is also applied externally on ulcers, boils, skin eruptions and on gums as a disinfectant.

\section{Collection and authentication of plant materials}

The heartwood of Acacia catechu willd was collected from the nearby forest Tada village, District Sagar (M. P.). The tree heartwood selected for the study was authenticated from the department of botany Dr. H. S. Gour University, Sagar (M. P.). Herbarium no. Bot./her/A/1158. After procuring the heartwood, materials were cleaned dried with proper aeration, turned over to ensure proper drying. The dried crude drugs were powdered and stored in well-closed labeled containers.

\section{Extraction}

The dried heartwood of acacia catechu wild was powdered, and $200 \mathrm{~g}$ of powder was taken and dissolved in $500 \mathrm{ml}$ distilled water in 1000 $\mathrm{ml}$ beaker. Then boiled for $15 \mathrm{~min}$ and kept for maceration for $24 \mathrm{~h}$ and filtered through the suction pump and the concentrated filtrate was collected and dried filtrate was used for formulation $[15,16]$.

\section{Formulation development (Mucoadhesive microspheres)}

\section{Methods}

Accurately weighted amount of the polymers carbopol, HPMC and sodium CMC were dissolved in $50 \mathrm{ml}$ acetone to form a homogeneous polymer solution Acacia catechu extract was then dispersed in it and mixed thoroughly. This phase containing drug was slowly poured at $150{ }^{\circ} \mathrm{C}$ into liquid paraffin containing $1 \%$ of span 80 stirring at $1000 \mathrm{rpm}$ to form an emulsion. After that, it was allowed putting in room temperature, and stirring was continued for acetone evaporation. Smooth discrete microspheres formed. The microspheres were collected by decantation and microspheres was washed with petroleum ether and stored in desiccators [17-19].

\section{Characterization of mucoadhesive microspheres}

\section{Stability studies of microspheres}

Stability study of microspheres was performed using following condition

1. Normal condition (room temperature $\left(25 \mathrm{C} \pm 2{ }^{\circ} \mathrm{C}\right)$

2. Stress condition $\left(40 \pm 5^{\circ} \mathrm{C}\right)$

3. Humidity condition $\left(7 \pm 5^{\circ} \mathrm{C}\right)$

4. Refrigerator $\left(5 \mathrm{C}-8{ }^{\circ} \mathrm{C}\right)$.

This study performed $30 \mathrm{~d}$, and microsphere drug content was determined (table 1).

\section{Surface electron microscopy (SEM)}

Surface electron microscopy performed for the shape and size study of microspheres. Morphology study of microspheres was performed using scanning electron microscopy (SEM).

Surface morphology of microspheres is determined by scanning electron microscopy. In this method, the microscope are mounted directly on the sample with the help of double-sided sticking tape and coated with a gold film. A small amount of microspheres are spread on the gold stub. After that, the sample stub placed in SEM. A scanning electron photograph is taken (fig. 1).

\section{In vitro drug release study}

The drug release study was performed for selected formulation. The mucoadhesive microspheres equivalent to $100 \mathrm{mg}$ was weighed and studied by using USP dissolution apparatus Type II (Rolex Tablet Dissolution Test Apparatus) in $900 \mathrm{ml}$ of $0.1 \mathrm{~N} \mathrm{HCl}$ dissolution media (pH-1.2) at $100 \mathrm{rpm}$ and $37{ }^{\circ} \mathrm{C}$ temperature. $1 \mathrm{ml}$ of sample was withdrawn at the predetermined time interval for $12 \mathrm{~h}$, and the same volume of fresh medium was replaced to maintained sink condition. Withdrawn samples were assayed spectrophotometrically at $279 \mathrm{~nm}$. The cumulative \% drug release was calculated using a standard calibration curve (fig. 2) [20-22].

\section{Pharmacological screening}

\section{Experimental animals}

Animal experimentation was conducted after getting approval from the institutional Animal ethics committee, which is registered with the committee, for the purpose of control and supervision of experiments on animals (CPCSEA) (SIPS/EC/2014/40). Wistar rats (180-200 g) were selected. The animals were grouped and housed in a polyacrylic cage and maintained under standard laboratory condition $\left(25 \pm 2{ }^{\circ} \mathrm{C}\right)$. They were allowed free access to standard dried pellet diet and water and libitum. Rats were acclimatized to laboratory conditions for $7 \mathrm{~d}$ before carrying out the experiments. All the experiments were carried out in a noise-free room between 08.00 to $15.00 \mathrm{~h}$. A separate group $(n=6)$ of rats was used for each set of experiments [23].

\section{Ethanol/HCl-induced gastric ulceration in rats (Chronic)}

The experiment was performed according to the method of Mizui and Dotuchi (1983) with certain modifications.180-200 g weight range rats were taken and fasted $24 \mathrm{~h}$. Drug and ulcer-causing agent were given in these schedule $1.5 \mathrm{ml}$ of ethanol/ $\mathrm{HCl}$ mixture $(70 \%$ ethanol and $5 \% \mathrm{HCl}$ ) were given on the first day, its half dose in the same volume on the second day and further half of the second dose in the same volume on the third day. Dose of microspheres Acacia catechu freshly prepared $(100 \mathrm{mg} / \mathrm{kg}$ per oral) was administered. Drug administration started from day 1 to 10 . One group was kept as vehicle control in which only vehicle, $1 \% \mathrm{CMC}$, was given whereas third groups were treated with cimetidine at $100 \mathrm{mg} / \mathrm{kg}$ per oral as a positive control. Feed was withdrawn $24 \mathrm{~h}$ before the last dose of the drug. One hour after the last dose, $1.5 \mathrm{ml}$ of ethanol/HCl mixture $(70 \%$ ethanol and $5 \% \mathrm{HCl}$ ) was given by intubation and the animals were sacrificed after 4 $\mathrm{h}$. The stomach was observed for percent Protection of ulcer score according to the scale already mentioned $[24,25]$.

\section{Acute toxicity study}

To determine acute oral toxicity studies (according to OECD guideline 423) were carried out on normal healthy rats, the method of acute oral toxicity at fixed doses was used. Acute oral toxicity studies were carried out on normal healthy rats, the method of acute oral toxicity at fixed doses was used. The microsphere Acacia catechu (50, $100,200,500,1000,2000 \mathrm{mg} / \mathrm{kg} /$ day) was administered orally for $4 \mathrm{~d}$ of six groups of rats $(n=6)$, and the animals were kept under observation for mortality as well as any behavioral changes for evaluation of a possible antiulcer effect.

Acute toxicity studies revealed that the plant extract was safe up to dose level of $2000 \mathrm{mg} / \mathrm{kg}$. There was no mortality or toxicity observed after oral administration of aqueous extracts acacia catechu willd. There was no sign of diarrhea, convulsion, salivation, tremors, lethargy, sleep or coma associated with oral toxicity. Animals did not show any sign of aggression, weakness, refusal of food, loss of weight or unusual behavior during handling. So, according to OECD, we select $1 / 10^{\text {th }}$ of a safe dose, $200 \mathrm{mg} / \mathrm{kg}$ and just half of it $100 \mathrm{mg} / \mathrm{kg}$ for comparative study [26].

\section{Groups}

Animals were maintained under the standard condition of temperature and humidity and underwent for an adaptation period of three days. The animals were divided into four groups $(n=6)$.

Group 1, as vehicle-treated, received normal saline solution;

Group 2, as negative control, received1.5 $\mathrm{ml}$ of ethanol/ $\mathrm{HCl}$ mixture (70\% ethanol and $5 \% \mathrm{HCl})$;

Groups 3, positive control, received cimetidine at $100 \mathrm{mg} / \mathrm{kg} \mathrm{p.} \mathrm{o.}$

Groups 4, received microsphere Acacia catechu freshly prepared (100 mg/kg p. o.) respectively. [27, 28]

\section{Chemicals}

Cimetidine used as a standard drug for comparative study with test groups (Mankind, India) was used in this study. All other chemicals and expedients were used in study standard quality.

\section{Statistical analysis of the data}

The values were expressed as mean \pm SEM. The statistical analysis was carried out by the one-way analysis of variance (ANOVA). 
Observation and results

A. Characterization of microspheres

Stability Study

Table 1: Stability studies of Sample in Environmental condition

\begin{tabular}{llllll}
\hline S. No. & Storage & Time (d) & \multicolumn{2}{l}{ Physical stability (Visual observation) } \\
\cline { 3 - 5 } & condition & & Color & State & Odour \\
\hline 1 & NC & Initial & NCC & NCC & NCC \\
2 & NC & One week (7th d) & NCC & NCC & NCC \\
3 & NC & Two weeks (14th d) & NCC & NCC \\
4 & NC & Three weeks (21st d) & NCC & NCC \\
5 & NC & Four weeks (28th d) & NCC & NCC \\
6 & SC & SC Initial & NCC & NCC & NCC \\
7 & SC & One week (7th d) & NCC & NCC \\
8 & SC & Two weeks (14th d) & NCC & NCC \\
9 & SC & Three weeks (21st d) & NCC & NCC \\
10 & SC & Four weeks (28th d) & NCC & \\
\hline
\end{tabular}

NC-Normal condition (e. g. room temperature $25 \mathrm{C} \pm 2 \mathrm{C}$ ), SC-Stress condition ( $40 \pm 5$ C, $\%$ RH-70 \pm 5 ), NCC-No change.

Scanning electron microscopy

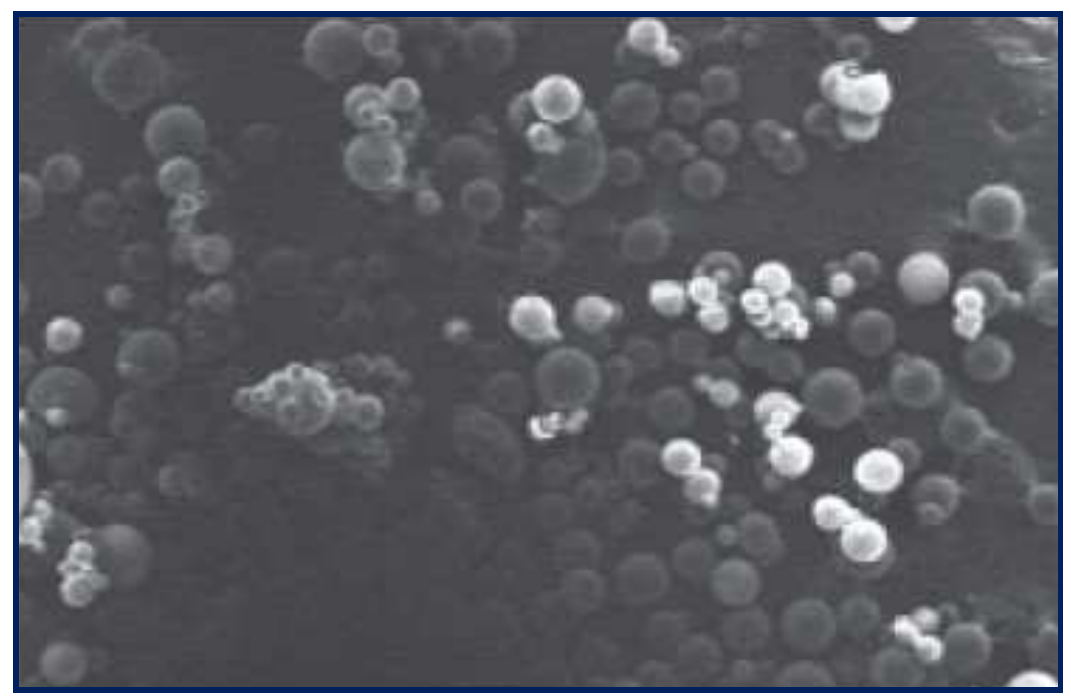

Fig. 1: Scanning electron microscopy of microsphere

In vitro drug release

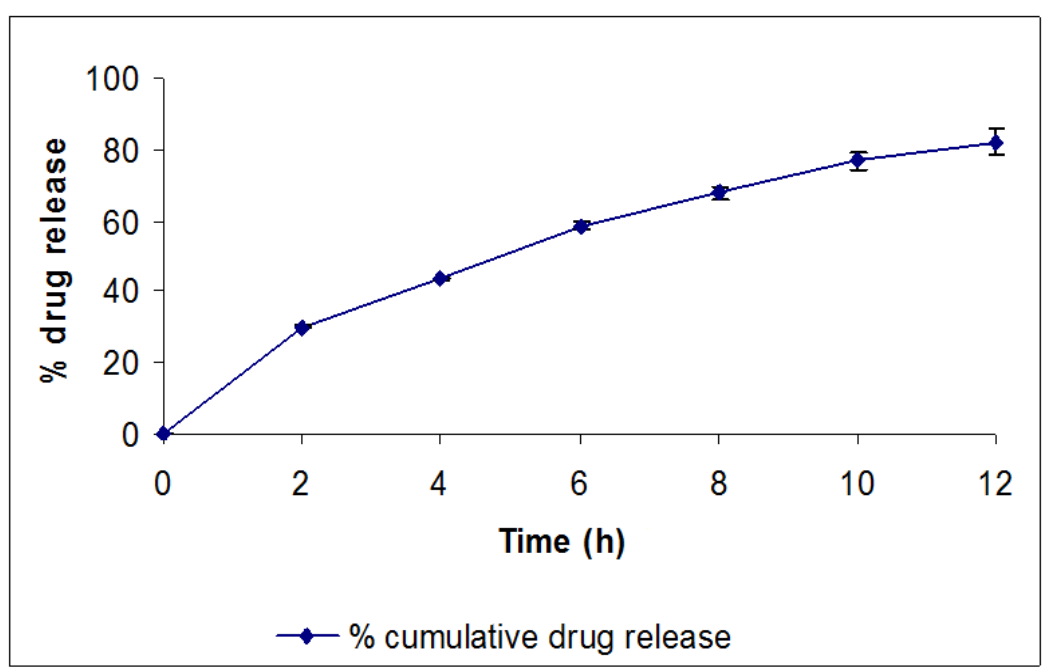

Fig. 2: In vitro drug release profile of microspheres 


\section{B. Pharmacological screening}

\section{Ulcerogenic effect (Ulcer index)}

Table 2: Anti-ulcerogenic effect of microsphere Acacia catechu against Ethanol/HCl induced ulcerogenic agents in rats

\begin{tabular}{ll}
\hline Treatment & Ulcer index \\
\hline Control (Nacl $0.9 \%)$ & $0.33 \pm 0.22$ \\
Negative Control(Etl/HCl $1.5 \mathrm{ml})$ & $21.56 \pm 0.95$ \\
Cimetidine (100 mg/kg p. o) & $6.83 \pm 1.25^{* * *}$ \\
Microsphere Acacia catechu (100 mg/kg p. o.) & $7.60 \pm 1.75^{* *}$ \\
Microsphere Acacia catechu (200 mg/kg p. o.) & $7.73 \pm 1.62^{* * *}$ \\
\hline
\end{tabular}

Values are expressed as mean \pm SEM $(\mathrm{n}=6)$. Percent inhibition calculated as compared to control group. $p$-Value*** $p<0.001(0$ ne-way ANOVA followed by Dunnett's test)

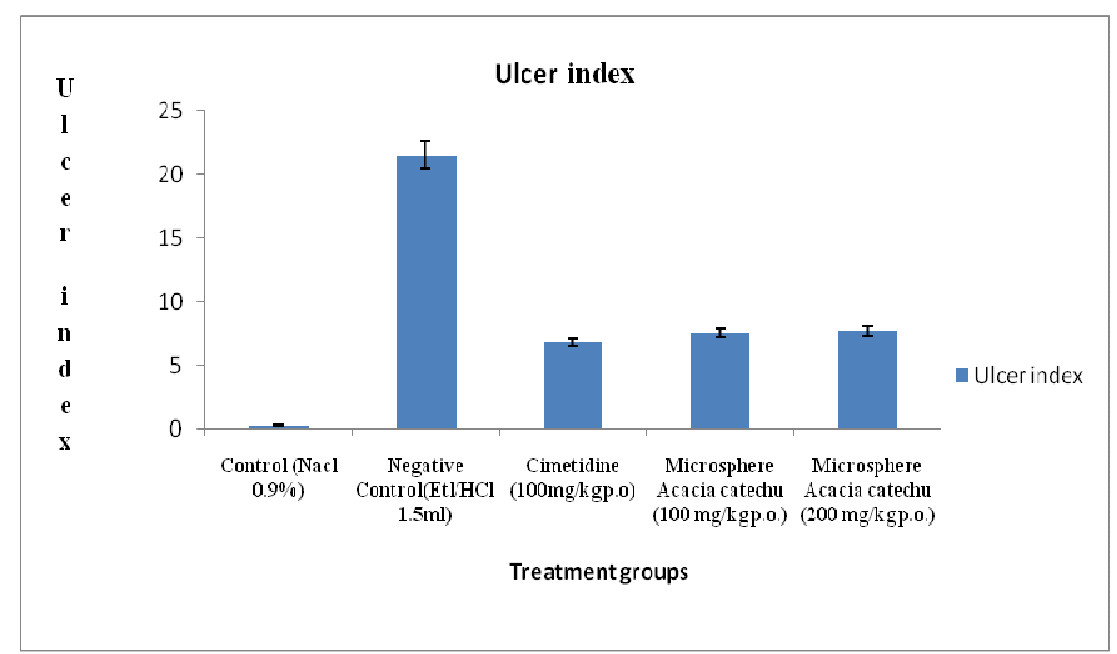

Fig. 3: Anti-ulcerogenic (Ulcer Index) effect of microsphere Acacia catechu against Ethanol/HCl induced ulcerogenic agents in rats

\section{pH and total acidity}

Table 3: pH and total acidity

\begin{tabular}{lll}
\hline Treatment & pH & Total acidity (mEq/l/100g) \\
\hline Control (Nacl 0.9\%) & $3.13 \pm 0.02$ & $0.00 \pm 0.00$ \\
Negative Control(Etl/HCl 1.5 ml) & $2.16 \pm 0.05$ & $100.33 \pm 3.06$ \\
Cimetidine (100 mg/kg p. o) & $6.83 \pm 0.25^{* * *}$ & $74.33 \pm 1.00^{* * *}$ \\
Microsphere Acacia catechu (100 mg/kg p. o.) & $3.60 \pm 0.35^{* *}$ & $81.50 \pm 3.03^{* *}$ \\
Microsphere Acacia catechu (200 mg/kg p. o.) & $4.78 \pm 0.47^{* * *}$ & $78.43 \pm 3.28^{* * *}$ \\
\hline
\end{tabular}

Values are expressed as the mean \pm SEM of six observations. ${ }^{* * *} P<0.001$ vs. control treatment (One-way ANOVA followed by Dennett's test).

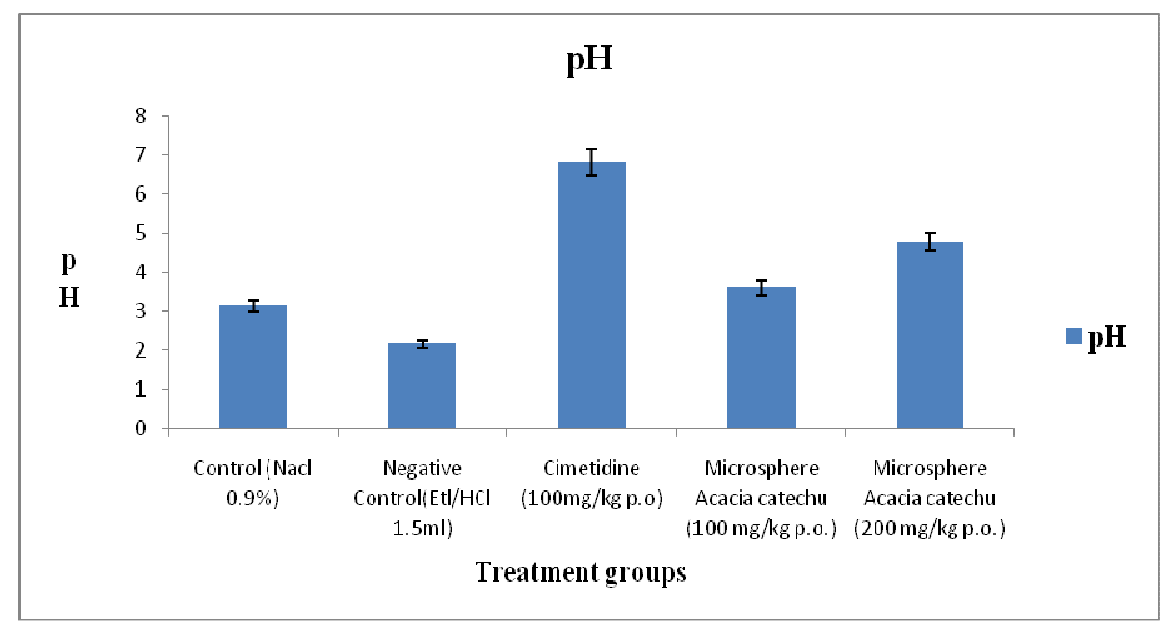

Fig. 4: Evaluation parameter for antiulcer-potential (pH) 


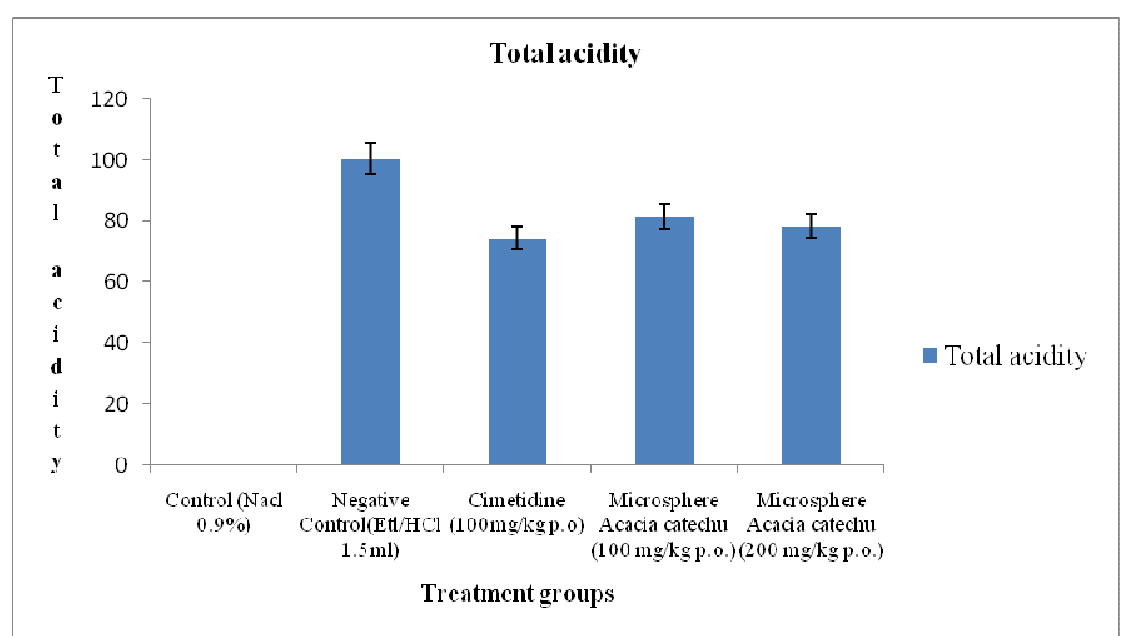

Fig. 5: Evaluation parameter for antiulcer-potential (total acidity)

\section{Histopathological studies}

The freshly excised stomachs were washed with saline and preserved in $10 \%$ formaldehyde solution for histopathological studies. The sections of stomachs were stained with hematoxylin and eosin, and permanent mounts of the tissues were prepared to investigate the histopathological changes. The microscopic slides were photographed.

Ulcers were induced in rats by oral administration of Ethanol/HCL $(1.5 \mathrm{ml})$, and microsphere Acacia catechu $(100 \mathrm{mg} / \mathrm{kg} \mathrm{p}$. o. and 200 $\mathrm{mg} / \mathrm{kg}$ p. o.) was administered orally prior to Ethanol/HCL treatment as described under "Materials and Methods." Rats were sacrificed, and the stomachs were sectioned for histological studies. Shown are the histological appearances of Vehicle control (A), saline-treated, Negative control (B), Ethanol/HCL-treated, Positive control (C), Cimetidine-pretreated Ethanol/HCL-treated and (D) microsphere Acacia catechu-pretreated Ethanol/HCL-treated 100 $\mathrm{mg} / \mathrm{kg}$ p. o. (E) microsphere Acacia catechu-pretreated Ethanol/ HCL-treated $200 \mathrm{mg} / \mathrm{kg} \mathrm{p}$. o. stained with hematoxylin and eosin at X10 magnifications $[29,30]$.

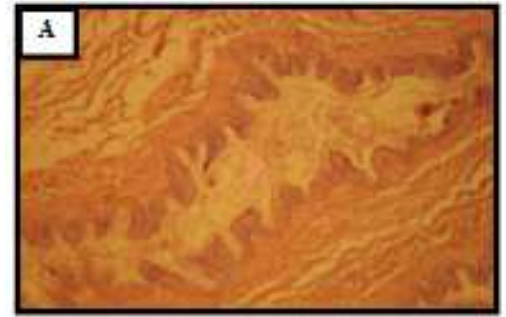

A. Control (Nacl)

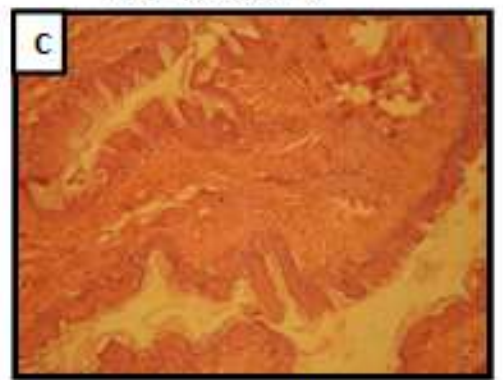

C. Cimetidine pretreated

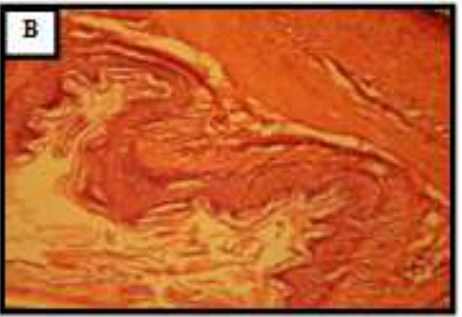

B. Negative control

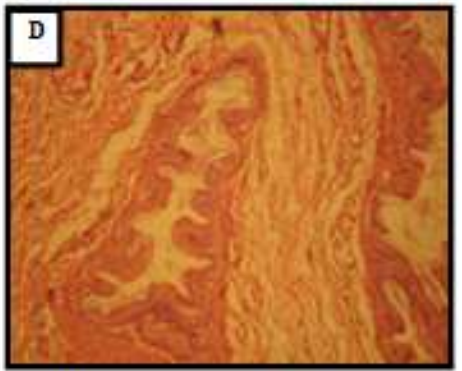

D. Acacia catechu $(100 \mathrm{mg} / \mathrm{kg})$

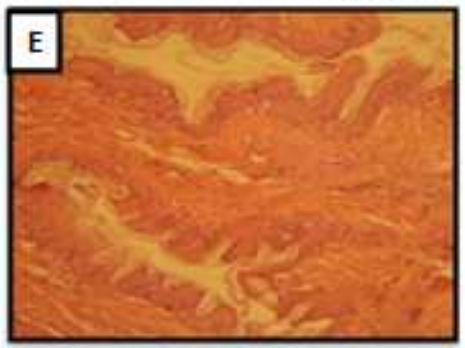

E. Acacia catschu $(200 \mathrm{mg} / \mathrm{kg})$

Fig. 6: Histology of rat gastric tissue after ulcer induction by Ethanol/HCL and protection by microsphere Acacia catechu 


\section{DISCUSSION}

Herbal drugs have received greater attention as an alternative to clinical therapy and the demand for these herbal remedies has greatly increased recently. The use of controlled release formulation also increases because the controlled release of provide the better therapeutic effect. Mucoadhesive microspheres has been accepted as a process to achieve controlled drug delivery by increasing the time of formulation at the site of absorption thereby improving and enhancing the bioavailability of drugs. Mucoadhesive drug delivery systems is one of the most important novel drug delivery systems with its various advantages, and it has a lot of potential in formulating dosage forms for various chronic diseases. Controlled release formulation of the herbal drug increase drug utilization of drug and provide better therapeutic effect without any side effect.

Although antiulcer agents are the mainstay in the treatment of ulcer and are effective in controlling gastric secretions, they have prominent side effects. There is needed to look for more efficacious agents control with lesser side effects. Controlled release formulation of the herbal drug is one of the thrust areas of research. Herbs consist of many bioactive compounds that are proved to be having good antiulcer activity.

The literature survey revealed that antiulcer activity is presented in Acacia catechu willd. As Acacia catechu willd is the drug highly valued in ayurvedic system of medication for various disorders so it was thought worthy to evaluate them for their antiulcer genic aspect using different models.

Acacia catechu tree distributed almost all over the India. The heartwood, bark, leaves of the plant possess having Anti-bacterial activity, Antisecretory activity, healing of wounds, Antioxidant, healing of a sore throat, gingivitis and Antidiabetic activity, antiinflammatory, antipyretic, antidiarrheal, antimicrobial, antiinflammation, antioxidant and antisecretory activities. The main objective of the present work is to develop of the controlled release formulation for ulcer control containing herbal drugs.

Controlled release formulations have provided drug release on site of action in a controlled and continuous manner. The strategies commonly used to obtain a maximum therapeutic effect by drug releasing in a controlling manner. There is not much research work done on herbal controlled release formulation in the treatment of peptic ulcer. Of all the controlled release dosage forms available, Microsphere represents an important particulate carrier system capable of delivering a drug on targeted site.

Mucoadhesive microspheres have been accepted as a process to achieve controlled drug delivery by prolonging the residence time of the dosage form at the site of absorption thereby improving and enhancing the bioavailability of drugs. Mucoadhesive drug delivery systems is one of the most important novel drug delivery systems with its various advantages, and it has a lot of potential in formulating dosage forms for various chronic diseases.

The use of these carriers as targeted drug delivery systems is associated with many advantages that include excellent storage stability, easy and large-scale productions. The formulation in microspheres confers stability, targeting, and sustained release of the incorporated molecules. Moreover, their control release provides a more therapeutic effect by using the natural herbal drug. The study aims in developing a novel particulate based approach to selective deliver a drug capable of releasing an herbal constituent in a controlled manner.

\section{Pharmacological screening}

\section{Acute oral toxicity studies}

Acute oral toxicity studies were carried out on normal healthy rats, the method of acute oral toxicity at fixed doses was used. The microsphere Acacia catechu $(50,100,200,500,1000,2000$ $\mathrm{mg} / \mathrm{kg} /$ day) was administered orally for $4 \mathrm{~d}$ of six groups of rats $(n=6)$, and the animals were kept under observation for mortality as well as any behavioral changes not occurs in the study.

\section{Ethanol-induced peptic ulcer}

The Ulcer index, gastric volume, free acidity, total acidity, and raised gastric $\mathrm{pH}$ significantly in comparison with Control group. Cimetidine, reference drug produced significant reduction in gastric ulcer and total acid output, the Mucoadhesive microspheres containing aqueous extracts of the Acacia catechu willd in the doses of $200 \mathrm{mg} / \mathrm{kg}$ produced a reduction in gastric $\mathrm{pH}$ as compared to control group.

From the above study, it is observed that Acacia catechu willd microspheres contain some active constituents like flavonoids which are responsible for its antiulcer activity. Also, it is observed aqueous extract microspheres maximum activity was found $(200 \mathrm{mg} / \mathrm{kg})$ with standard cimetidine $(100 \mathrm{mg} / \mathrm{kg})$.

Microspheres of Acacia catechu willd for antiulcer potency in Ethanol-induced models taken up for the study. From the results, it reveals that aqueous extract microspheres at $200 \mathrm{mg} / \mathrm{kg}$ had reduced ulcer incidence significantly when compared to the control as evident by the decrease in ulcer score in the model.

\section{CONCLUSION}

It is generally accepted that gastric ulcers results from an imbalance between aggressive factors and the maintenance of the mucosal integrity through the endogenous defense mechanism. Peptic ulcer results due to overproduction of gastric acid or decrease in gastric mucosal production. Ethanol-induced ulcers are due to autodigestion at the gastric mucosa and breakdown of the gastric mucosal barrier. In the case of ethanol-induced, ulcer formation is mainly due to the acid activity. An Increase in acid secretion and back diffusion at $\mathrm{H}^{+}$ions is also noticed. It is reasonable to assume that the observed gastric mucosal lesions induced by ethanol acid reaction which damage the mucous membrane of the stomach. Protection against ulcerations in Ethanol induced ulcer model indicates cytoprotective action by extracts microspheres. Antisecretory activity of the extracts microspheres was noticed in ethanol-induced ulcer model. There was a decrease in gastric volume and reduction in free and total acidity in the animals treated with aqueous extracts microspheres and was found to be devoid of ulcerogenic potential. The above discussion shows that the Acacia catechu microspheres is said to produce beneficial antiulcer activity. The acute toxicity study conducted for aqueous extracts indicates that they are safe up to $2000 \mathrm{mg} / \mathrm{kg}$ body weight. Aqueous extract microspheres at dose $200 \mathrm{mg} / \mathrm{kg}$, has reduced ulcer incidence when compared to the control as evident by the decrease in ulcer score in Ethanol-induced Models. There was a decrease in gastric volume and reduction in free and total acidity in the animals treated with aqueous extracts. The extracts of Acacia catechu willd were found to possess antiulcer activity due to the presence of flavonoids and tannins in them. Thus the present study was an attempt to evaluate aqueous and extract of the acacia catechu willd microspheres for its antiulcer activity. Phytochemical studies of the extracts were carried out, and extracts showed the presence of alkaloids, flavonoids, tannins. The interpretation of the results was done after subjecting the data obtained from various studies to statistical analysis which included one way ANOVA followed by post tests like Dunnets and Tukeys. The studies indicated that the microspheres loaded with aqueous extracts of Acacia catechu willd produced promising antiulcer activity.

\section{ACKNOWLEDGMENT}

All the authors are highly grateful to SIPS, Sagar (M. P) for providing all the facilities required for the completion of the work.

\section{AUTHORS CONTRIBUTIONS}

All the authors have contributed equally

\section{CONFLICT OF INTERESTS}

Declared none

\section{REFERENCES}

1. Asmara Hassan, Salma Rahman, Farah Deeba, Shahid Mahmud. Antimicrobial activity of some plant extracts having hepatoprotective effects. J Med Plants Res 2009;3:20-3. 
2. Asolkar LV, Kakkar KK. Second supplement to a glossary of indian medicinal plants with active principles. Part I. Publication and Information Directorate (CSIR), New Delhi; 1992. p. 201-3.

3. B Guizot, DJ Armstrong, PNC Elliot, JL Ford, C Rostron. Investigation of in vitro release characteristics of NSAID-loaded polylactic acid microspheres. J Microencapsulation 1996:13:701-8.

4. Bancroft JD, Cook BC. Manual of histological techniques. Churchill Livingstone, Edinburgh NY, Baron JH. Current views of the pathogenesis of peptic ulcer. Stand J Gastroenterol 1984. p. 7-20.

5. Bimla, Meera, Chander, Jagdish, Kalidhar SB. A review on the chemistry and bioactivity of acacia spp. J Med Aromatic Plants Sci 2005;3:51-90.

6. Friedman GD, Siegelaub AB, Seltzer C. Cigarettes, alcohol, coffee, and peptic ulcer. N Engl J Med 1974;290:469-73.

7. Sontag S, Graham DY, Belisto A. Cimetidine, cigarette smoking, and recurrence of duodenal ulcer. Med 1984;311:689-93.

8. Srivastava AK, Ridhurkar DN, Wadhwa S. Floating microspheres of cimetidine: formulation, characterization and in vitro evaluation. Acta Pharm 2005;55:277-85.

9. Kurata JH, Honda GD, Frankl H. Hospitalization and mortality rates for peptic ulcers: a comparison of a large health maintenance organization and the United States data. Gastroenterology 1982;83:1008-16.

10. Gattani YS, Bhagwat DA, Maske AP. Formulation and evaluation of intragastric floating drug delivery system of diltiazem hydrochloride. Asian J Pharm 2008;2:228-31.

11. Gledhill T, Howard OM, Buck M. Single nocturnal dose of H, receptor antagonist for the treatment of duodenal ulcer. Gut 1983;24:904-8.

12. Lakshmi T, Geetha RV, Roy Anitha. In vitro evaluation of antibacterial activity of acacia catechu willd heartwood extract. Int J Pharma Biosci 2012;2:12.

13. Evans WC, Trease Pharmacognosy. 16th ed. London: Saunders Elsevier; 2009. p. 232-4.

14. Kokate CK, Purohit AP, Gokhle S. B Pharmacognosy $13^{\text {Th }}$ edition Pune Nirali Prakashan; 2007. p. 124.
15. Lakshmi T, Geetha RV, Roy Anita. Acacia catechu willd-a pharmacological review. Int J Curr Res Rev 2011;3:1380-9.

16. Lam SK, Isenberg JI, Grossman MI. Rapid gastric emptying in duodenal ulcer patients. Dig Dis Sci 1982;27:598-604.

17. Malagelada JR, Lonstreth GF, Deering TB. Gastric secretion and emptying after ordinary meals in duodenal ulcer. Gastroenterology 1977;73:989-94.

18. McCoy RF, Greenberg GR, Baron JH. Duodenal pH in health and duodenal ulcer disease. Gut 1984;25:386-92.

19. Patel, Jayshree, Vipin, Shreyas. Antimicrobial screening and phytochemical analysis of the resin part of Acacia catechu pharmaceutical. Biol J 2009;47:34-7.

20. Mendel A. What has been happening to a duodenal ulcer? Gastroenterology; 1974. p. 1020-2.

21. Mizui T, Dotuchi M. Effect of polyamines on acid and an ethanolinduced gastric lesion in rats. Japan J Pharmacol 1983;33:939-45.

22. Naik GH, Priyadarsini KI, Satav JG, Banavalikar MM, Sohoni DP, Biyani MK, et al. the Comparative antioxidant activity of individual herbal components used in Ayurvedic medicine. Phytochemistry 2003;63:97-104.

23. Patil SS, Bhide AA, Gorle AM. Antiulcer activity and Antiinflammatory studies on acacia catechu. Indian Drugs 2010;47:52-3.

24. Rao PR, Seshadri TR. Epi-catechin from Acacia catechu. J Sci Indian Res 2008;2:59.

25. SK Bhattacharya. Hand Book of Medicinal Plants. Pointer publishers, Jaipur; 2001. p. 230.

26. Sethi RK, Guru P, Sahu SK, Das PK, Barik B. Design and development of drug loaded microsphere by utilizing emulsion solvent evaporation method. Int J Pharm Sci 2010;1:46-9.

27. Sharma P, Dayal R, Ayyer KS. Acylglucosterole from Acacia catechu. J Med Aromatic Plants Sci 1999;21:1002-5.

28. Wallis TE. Textbook of pharmacognosy, CBS Publishers and Distributors, New Delhi. 5th Edition; 2011. p. 133-7.

29. Pramod Kumar, Shahid H Ansari, Javed Ali. Herbal remedies for the treatment of periodontal disease-a patent review recent patents on drug delivery and formulation 2009;3:221-8.

30. Price WA, Grizzle JA, Postlewait RW. Results of operation for duodenal ulcer; 1970;131:233-44. 